NBER WORKING PAPER SERIES

\title{
EXPORTING AND ORGANIZATIONAL CHANGE
}

\author{
Lorenzo Caliendo \\ Ferdinando Monte \\ Esteban Rossi-Hansberg \\ Working Paper 23630 \\ http://www.nber.org/papers/w23630 \\ NATIONAL BUREAU OF ECONOMIC RESEARCH \\ 1050 Massachusetts Avenue \\ Cambridge, MA 02138 \\ July 2017
}

We thank Francis Kramarz for helpful comments and suggestions. The views expressed herein are those of the authors and do not necessarily reflect the views of the National Bureau of Economic Research.

At least one co-author has disclosed a financial relationship of potential relevance for this research. Further information is available online at http://www.nber.org/papers/w23630.ack

NBER working papers are circulated for discussion and comment purposes. They have not been peer-reviewed or been subject to the review by the NBER Board of Directors that accompanies official NBER publications.

(C) 2017 by Lorenzo Caliendo, Ferdinando Monte, and Esteban Rossi-Hansberg. All rights reserved. Short sections of text, not to exceed two paragraphs, may be quoted without explicit permission provided that full credit, including $\left({ }^{\circ}\right.$ notice, is given to the source. 
Exporting and Organizational Change

Lorenzo Caliendo, Ferdinando Monte, and Esteban Rossi-Hansberg

NBER Working Paper No. 23630

July 2017

JEL No. D22,F1,F16,J24,J31,L23

\begin{abstract}
$\underline{\text { ABSTRACT }}$ responds to opportunities in export markets.

Lorenzo Caliendo

Yale University

School of Management

135 Prospect Street

New Haven, CT 06520

and NBER

lorenzo.caliendo@yale.edu

Ferdinando Monte

Georgetown University

McDonough School of Business

37 th \& O Streets, NW

Washington, DC 20057

ferdinando.monte@georgetown.edu

\author{
Esteban Rossi-Hansberg \\ Princeton University \\ Department of Economics \\ Fisher Hall \\ Princeton, NJ 08544-1021 \\ and NBER \\ erossi@princeton.edu
}

We study the effect of exporting on the organization of production within firms. Using French employer-employee matched data together with data on a firm's exporting activity, we find that firms that enter the export market and expand substantially reorganize by adding layers of management, hiring more and paying, on average, lower wages to workers in all pre-existing layers. In contrast, firms that enter the export market and expand little do not reorganize and pay higher average wages in all pre-existing layers. We then present some evidence that these effects are causal using pre-sample variation in the destination composition of exports, in conjunction with real exchange rate variation across countries. Our results are consistent with a growing literature using occupations to study the internal structure of firms and how their organization 


\section{Introduction}

Exporting affects the organization of production. In order to produce at the scale needed to access export markets, firms need to hire teams of workers with a different set of skills, pay them different wages, and give them different roles within the organization. In this paper we explore how a firm's organization reacts to new or improved export opportunities. Guided by the theory of knowledgebased hierarchies, ${ }^{1}$ we understand organization as the characteristic and roles played by the workers within a firm. Hence, we explore how the number of management layers, as well as the number of workers and wages in each of these layers, change when the firm starts exporting or expands its presence in foreign markets. Our goal is to document these relationships and attempt to rationalize them using available theories. Given that these reorganizations have important implications for the size, hiring practices, and productivity of exporting firms, the findings are relevant to understand the overall effects of trade liberalizations, as demonstrated by Caliendo and Rossi-Hansberg (2012, from now on $\mathrm{CRH}$ ).

We follow the work in Caliendo, Monte and Rossi-Hansberg (2015, from now on CMRH) that uses matched employer-employee data to document empirically how firms change their organization when they grow. The paper identifies four hierarchical layers of the firm using a French classification of occupations (PCS) based on an occupation's hierarchical position in the firm. That paper shows that firms actively manage their organizational structure. When they grow substantially, they reorganize by adding a layer of management,${ }^{2}$ lowering average wages in all preexisting layers of the firm (including the layer of workers), and hiring more employees in all of these layers. In contrast, when they grow little, they tend not to reorganize, and so they grow by adding workers in preexisting layers and increasing average wages. This behavior can be rationalized using the theory of knowledge-based hierarchies. Firms that grow substantially want to economize on costly knowledge by concentrating it into a few managers and lowering the knowledge of workers that do more routine tasks. Hence they add a management layer and lower skill, and consequently average wages, in preexisting layers. Firms that grow little do not find this change profitable since it requires a more costly management structure, so they prefer to grow by hiring more and better workers and managers in preexisting layers that require less managerial help. In follow up work, using Portuguese data, Caliendo, Mion, Opromolla and Rossi-Hansberg (2015) confirm these findings for an additional country, but more importantly, show that they are associated with changes in quantity-based measures of productivity of the firm. So, reorganizations that add layers also increase the ability of the firm to transform inputs into physical units of output.

None of our work so far, however, has studied empirically the relationship between organization and exporting. This is our aim in this paper using the same French dataset that we used in CMRH. This data covers the vast majority of French manufacturing firms during the period 2002-2007. ${ }^{3}$

\footnotetext{
${ }^{1}$ As initially proposed by Rosen (1982) and Garicano (2000) and used in the context of heterogeneous firms in Caliendo and Rossi-Hansberg (2012).

${ }^{2}$ Adding a layer is identified empirically as hiring an agent in an occupation classified in a layer where the firm did not hire before.

${ }^{3}$ We refer the reader to CMRH for a detailed description of this data.
} 
We start by exploring the organization of exporters relative to non-exporters. Exporters are larger, employ more hours of labor, pay higher wages, and have more layers. Firms with more layers are much more likely to be exporters. For example, among firms with three layers of management (the highest number of layers given that they also have a layer of workers), $90.2 \%$ of the value added is generated by firms that also export. All of these facts are consistent with the standard finding in the literature that exporters are larger and are also consistent with $\mathrm{CRH}$ where larger firms have weakly more layers. Hence, it is perhaps more interesting to turn our attention to new exporters.

We find that new exporters are more likely to add layers than non-exporters (and symmetrically firms that exit exporting are more likely to drop layers). In addition, new exporters that add layers decrease average wages in existing layers while exporters that do not add layers increase them. The well-known finding (see Bernard and Jensen 1995, 1997, and Verhoogen 2008) that firms that become exporters pay higher wages is the result of a composition effect. In fact, the firms that expand significantly as a result of exporting, namely, the ones that add layers, reduce average wages. Furthermore, they do so at all pre-existing layers. In contrast, new exporters that do not change layers barely expand but do increase wages. Since there are more new exporters that do not change layers than there are exporters that do change layers, the average effect on wages is positive but small. The result is relevant for the conceptualization of new exporters. The notion that new exporters expand and increase the wages of their employees either because they upgrade their technology (and so the marginal product of labor is higher) or because profits are higher and they share them with workers (via a wage sharing or bargaining mechanism) is at odds with our data. ${ }^{4}$ The data are consistent with a view in which new exporters that expand significantly change their organizational design and economize on knowledge by employing less knowledgeable employees who are paid less.

The findings above do not document the causal effect of exporting on organization, but rather the fact that exporting and organizational change are related in the data. To try to measure the causal effect of exporting on organization, we exploit pre-sample variation in the destination composition of a firm's exports, in conjunction with real exchange rate variation across countries, to build an instrument for exports. Similar instruments were used by Bertrand (2004), Brambilla et al. (2012), Revenga (1992), and Verhoogen, (2008). We then use this instrument to evaluate if the probability of adding layers is causally related to increases in exports. We find that the first stage is somewhat noisy and weak across the subsamples of firms with different numbers of layers, but the second stage shows that for firms with one, two or three layers exporting does increase the probability of adding layers significantly. The result is not significant for firms with four layers, perhaps due to the fact that our identification of layers in the data allows for a maximum of only four layers so those firms can only reduce the number of layers. Perhaps more interesting is that, using this instrument, the causal effect of increases in the number of layers due to better access to foreign markets is to reduce wages in preexisting layers and to increase the number of employees

\footnotetext{
${ }^{4}$ Felbermayr, et al. (2008), Egger and Kreickemeier (2009), Helpman, et al. (2010) and Eaton, et al. (2011a) propose models were the exporter-wage premium is the outcome of a bargaining mechanism.
} 
in all of them. This holds for all layers in firms with any number of layers. More work is needed to establish this causality definitively, and we discuss several other papers that have tried to do so with other samples of firms and countries in Section 5, but this evidence is, we believe, encouraging.

The rest of the paper is organized as follows. Section 2 reproduces some of the theory in CRH to clarify the logic behind the relationships that we look for in the data. Section 3 presents the empirical description of the relationship between organization and exporting. Section 4 represents our causal results and Section 5 reviews the related literature using occupations to understand the organization of the firm and its relationship to foreign markets in a variety of countries. Section 6 concludes.

\section{Exports and Reorganization: Theoretical Implications}

In this section we discuss briefly the framework in CRH. Given that the purpose of the current paper is to describe and understand the data, we present the theory in its simplest form and do not discuss all the details fully. The interested reader is directed to $\mathrm{CRH}$ for the more technical discussions and all proofs of the results.

We consider an economy with $N$ identical agents. Agents acquire knowledge in order to solve the problems they encounter during production. Agents that acquire more knowledge command higher wages according to a function $w(z)$ with $\partial w(z) / \partial z>0 .^{5}$

Firms are started and organized by a CEO. She pays a fixed entry cost $f^{E}$ in units of labor to design her product. After doing so, she obtains a demand draw $\alpha$ from a known distribution $G(\alpha)$. The draw $\alpha$ determines the level of demand of the firm. If the entrepreneur decides to produce, she pays a fixed cost $f$ in units of labor. Production requires labor and knowledge. Agents employed in a firm act as production workers (layer $\ell=0$ ) or managers (layers $\ell \geq 1$ ). We denote by $n_{L}^{\ell}, z_{L}^{\ell}$, and $w_{L}^{\ell}$, the number, knowledge, and total wage of employees at layer $\ell=0,1,2 \ldots$ of an organization with $L$ layers of management (or $L+1$ layers of employees, given that we call the layer of workers layer zero). Workers use their unit of time to generate a production possibility that can yield one unit of output. For output to be realized, the worker needs to solve a problem drawn from a distribution $F(z)$ with $F^{\prime \prime}(z)<0$. Workers learn how to solve the most frequent problems, the ones in the interval $\left[0, z_{L}^{0}\right]$. If the problem they face falls in $\left[0, z_{L}^{0}\right]$, production is realized; otherwise, they can ask a manager one layer above how to solve the problem. Managers spend $h$ units of their time on each problem that gets to them. A manager at layer $\ell=1$ tries to solve the problems workers could not solve. Hence, they learn how to solve problems in $\left[z_{L}^{0}, z_{L}^{0}+z_{L}^{1}\right]$. In general, the firm needs $n_{L}^{\ell}=h n_{L}^{0}\left(1-F\left(Z_{L}^{\ell-1}\right)\right)$ managers of layer $\ell$, where $Z_{L}^{\ell}=\sum_{l=0}^{\ell} z_{L}^{l}{ }^{6}{ }^{6}$

Let $C(q ; w)$ denote the minimum variable cost of producing $q$ units, and $C_{L}(q ; w)$ the same

\footnotetext{
${ }^{5}$ In $\mathrm{CRH}$ the wage is interpreted as the compensation for the time endoment of the workers, $\bar{w}$, plus the compensating differential for the cost of acquiring knowledge. Learning how to solve problems in an interval of knowledge of length $z$ costs $\bar{w} c z$ ( $c$ teachers per unit of knowledge at cost $\bar{w}$ per teacher). Hence, the total wage of an employee with knowledge $z$ is given by $w(z)=\bar{w}[c z+1]$.

${ }^{6}$ To derive some of the implications of the theory, CRH specify the distribution of problems as an exponential, so $F(z)=1-e^{-\lambda z}$.
} 
cost if we restrict the organization to producing with $L$ layers of management, in an economy with an equilibrium wage function $w(\cdot)$. Then, the organizational problem of the firm is given by,

$$
C(q ; w)=\min _{L \geq 0}\left\{C_{L}(q ; w)\right\}=\min _{L \geq 0,\left\{n_{L}^{\ell}, z_{L}^{\ell}\right\}_{l=0}^{L} \geq 0} \sum_{\ell=0}^{L} n_{L}^{\ell} w_{L}^{\ell}
$$

subject to

$$
\begin{aligned}
q & \leq F\left(Z_{L}^{L}\right) n_{L}^{0} \\
w_{L}^{\ell} & =w\left(z_{L}^{\ell}\right) \text { for all } \ell \leq L \\
n_{L}^{\ell} & =h n_{L}^{0}\left[1-F\left(Z_{L}^{\ell-1}\right)\right] \text { for } L \geq \ell>0, \\
n_{L}^{L} & =1
\end{aligned}
$$

So one entrepreneur, $n_{L}^{L}=1$, chooses the number of layers, $L$, employees at each layer, $n_{L}^{\ell}$, and the interval of knowledge that they acquire, $z_{L}^{\ell}$, subject to the output constraint (2), the prevailing wage function (3) and the time constraints of employees at each layer (4).

The problem above has several implications on the internal organization of firms as they grow. Consider first the choices $z_{L}^{\ell}$ and $n_{L}^{\ell}$ as function of $q$, but conditional on $L$. That is, consider a firm that decides to produce more without changing the number of layers, that is, without reorganizing. To expand production, the firm needs to increase either total knowledge, $Z_{L}^{L}$, or the number of workers, $n_{L}^{0}$. Since knowledge and the number of workers are linked through the time constraint (4), the firm does a bit of both. The only way to have more workers is to make them more knowledgeable so they ask less often and the CEO can have a larger span of control. Since the knowledge of agents at different layers is complementary, the firm does so at all layers. Hence, the number of workers in all layers increases, as does the knowledge and, consequently, wages of all workers. Note also that since every worker has to learn more in order to expand the firm, the marginal cost of production is increasing in quantity conditional on the number of layers $\left(\partial^{2} C_{L}(q ; w) / \partial q^{2}=\partial M C_{L}(q ; w) / \partial q>0\right)$. It is increasingly costly to expand production in an organization with a fixed organizational structure as reflected by the number of layers.

In contrast, as proven in $\mathrm{CRH}$, as firms increase the number of layers by one in order to produce more, the number of agents in each layer increases and the knowledge in all pre-existing layers, and therefore the wage, decreases. The logic is straightforward. Firms add layers to economize on the knowledge of their workers. So when they add a new top layer, they make the new manager deal with the rare problems and make lower level employees know less, and consequently they pay them less. The lower knowledge in all pre-existing layers reduces, by equation (4), the span of control of each manager in the organization. However, the number of employees in all layers still goes up since the span of control of the new top manager is larger than one. The marginal cost also declines discontinuously at the quantity produced where the firm adds a layer. The organization is building capacity by adding an extra layer, and that reduces the marginal cost discontinuously.

So far we have not said anything about how the quantity produced is determined. To do so we need to turn to the profit maximization and entry decision of the firm. CRH embed the cost function 
discussed above into a standard Melitz (2003) type framework with heterogeneity in demand. The model in CRH also allows us to study the effect of a new opportunity to export on the organization of firms. We sketch some of those arguments here.

We now embed our economy, that we denote by $i$, in a world with $J$ foreign countries, with typical index $j$. Let $x_{i j}(\alpha)$ be the quantity demanded of an agent in country $j$ for good $\alpha$ produced in country $i$, and let $p_{i j}(\alpha)$ denote its price. The name of the good $\alpha$ is also a demand shifter that implies that agents like varieties with higher $\alpha$ better. So that with constant elasticity of substitution (CES) preferences with elasticity of substitution $\sigma>1$,

$$
x_{i j}(\alpha)=\alpha\left(\frac{p_{i j}(\alpha)}{P_{j}}\right)^{-\sigma} \frac{R_{j} / N_{j}}{P_{j}}
$$

where $P_{j}, R_{j}$ and $N_{j}$ denote the price index, total revenue and population in country $j$.

CEOs in the domestic country pay a fixed cost $f_{i i}$ to produce. If they want to supply the foreign market, they also need to pay a fixed cost $f_{i j}$. Trading goods is costly. Let $\tau_{i j}>1$ be the 'iceberg' trade cost incurred by firms exporting to market $j$. Consider the problem of a firm with demand draw $\alpha$ in country $i$ that does not export. It solves,

$$
\pi_{i}(\alpha) \equiv \max _{\left(x_{i i},\left\{x_{i j}\right\}_{J}\right) \geq 0}\left\{p_{i i}(\alpha) N_{i} x_{i i}(\alpha)+\sum_{J} p_{i j}(\alpha) N_{j} x_{i j}(\alpha)-C\left(q_{i}(\alpha) ; w_{i}\right)-f_{i i}-\sum_{J} f_{i j}\right\}
$$

subject to $(6)$, where

$$
q_{i}(\alpha)=N_{i} x_{i i}(\alpha)+\sum_{J} \tau_{i j} N_{j} x_{i j}(\alpha) .
$$

The cost function $C\left(\cdot ; w_{i}\right)$ solves the cost minimization problem described above. The first-order conditions of this problem implicitly define the quantities sold in each market,

$$
N_{i} x_{i i}(\alpha)=\alpha R_{i} P_{i}^{\sigma-1}\left(\frac{\sigma}{\sigma-1} M C\left(q_{i}(\alpha) ; w_{i}\right)\right)^{-\sigma}
$$

and

$$
N_{j} x_{i j}(\alpha)=\alpha R_{j} P_{j}^{\sigma-1}\left(\frac{\sigma}{\sigma-1} \tau_{i j} M C\left(q_{i}(\alpha) ; w_{i}\right)\right)^{-\sigma} .
$$

In contrast with the standard model, $x_{i i}(\alpha)$ and $x_{i j}(\alpha)$ enter the marginal cost function through $q_{i}(\alpha)$ as well. That is, a firm's level of total production affects its marginal cost and therefore how much it sells in each market. Importantly, the decision to export affects the cost of production of the goods sold in the local market. ${ }^{7}$ Hence, as usual, the price in each market is given by a constant markup over marginal cost, namely,

$$
p_{i j}(\alpha)=\frac{\sigma}{\sigma-1} \tau_{i j} M C\left(q_{i}(\alpha) ; w_{i}\right)=p_{i i}(\alpha) \tau_{i j}
$$

\footnotetext{
${ }^{7}$ This implies that even when $f_{i j}>f_{i i}$ all firms in the economy could enter the exporting market. Of course, if $f_{i j}$ is large enough, then only the most productive firms will export. This is a key distinction with Melitz (2003) where, for the case of two symmetric countries, all firms will export if and only if $f_{i j} \leq f_{i i}$.
} 
Note that, as we argued above, since $\partial M C_{L}(q ; w) / \partial q>0$ the price of firms that expands increases conditional on the number of layers and declines discontinuously with a reorganization. Furthermore, a firm that starts to export to a new market, as a result of a marginal increase in $\alpha$ or an idiosyncratic reduction in $\tau_{i j}$ or $f_{i j}$, increases $q_{i}(\alpha)$, which results in higher marginal cost, higher wages and more employees in all layers, if the firm does not reorganize. However, if exporting to the new market makes the firm add a layer, it will reduce its marginal cost discontinuously which will decrease its price and expand its quantity more than in the previous case. The reorganization is accompanied by reductions in knowledge and wages in all preexisting layers, and increases in the number of workers in all layers, as discussed above.

To sum up, the model has the following implications.

1. Exporters are larger and have more layers than non-exporters.

2. A firm that becomes an exporter, or enters a new export market, as a result of a marginally higher $\alpha$ or marginally lower $\tau_{i j}$ or $f_{i j}$ for some $j$,

(a) increases $L$ weakly;

(b) if $L$ does not change, it increases $w_{L}^{\ell}$ and $n_{L}^{\ell}$ at all $\ell$;

(c) if $L$ increases it decreases $w_{L}^{\ell}$ and increases $n_{L}^{\ell}$ at all $\ell$;

Armed with these implications, we now turn to our empirical analysis.

\section{Exporting and Firm Organization: Evidence from France}

We use confidential data collected by the French National Statistical Institute (INSEE) for the period 2002 to 2007. It combines the BRN dataset with manufacturing firm balance-sheet information with the DADS which includes worker characteristics. The details of the data construction can all be found in CMRH. Our sample includes 553,125 firm-year observations in the manufacturing sector and all monetary values are expressed in 2005 euros.

We use the PCS-ESE classification codes for workers in the manufacturing sector to identify the hierarchical layer in the firm. For manufacturing, it includes five occupational categories given by:

2. Firm owners receiving a wage (which includes the CEO or firm directors).

3. Senior staff or top management positions (which includes chief financial officers, heads of human resources, and logistics and purchasing managers).

4. Employees at the supervisor level (which includes quality control technicians, technical, accounting, and sales supervisors).

5. Qualified and non-qualified clerical employees (secretaries, human resources or accounting employees, telephone operators, and sales employees). 
6. Blue collar qualified and non-qualified workers (welders, assemblers, machine operators and maintenance workers).

As in $\mathrm{CMRH}$ we merge classes 5 and 6 , since the distribution of wages of workers in these two classes is extremely similar. Hence a firm can have a maximum of four layers, three of management and one of workers. We refer to the number of layers in the firm by the number of management layers. So a firm that has a layer of workers and one layer of managers is referred to as a firm with one layer.

\subsection{Cross-sectional Comparisons between Exporters and Non-Exporters}

It is well known by now that exporters are larger in terms of value added and employment (see Bernard and Jensen, 1999, and Bernard, et al., 2007, among others). This is clearly the case in our data as well. ${ }^{8}$ They also pay slightly higher wages. As Table 1 shows, they have more layers of management as well. The average number of layers of management among non-exporters is 1.25, meaning that the average exporter has a layer of workers, a layer of management and a fraction of a second layer of management. If we look at exporters, they have 2.11 layers of management on average. Hence, as we would expect from the fact that they are larger, exporters have more layers.

Table 1: Description of exporters

\begin{tabular}{ccccc}
\hline & \multicolumn{4}{c}{ Average } \\
\cline { 2 - 5 } & VA & Hours & Wage & \# of layers \\
\hline Non-exporters & 667.97 & $24,112.07$ & 23.06 & 1.25 \\
Exporters & $6,754.35$ & $164,534.30$ & 23.71 & 2.11 \\
\hline \hline
\end{tabular}

The difference in wages is significant at $1 \%$.

In figure 1 we present the distribution of value added by layer and by export status. For firms with a given number of layers, each of the panels compares the distribution of exporters and nonexporters. As can be seen from comparing the dark lines across panels, firm with more layers have a distribution of value added with a higher mean. We document this carefully in CMRH. Our emphasis in this paper is the comparison between exporters and non-exporters. Clearly, for all layers exporters tend to be larger in terms of value added. The size advantage of exporters is there conditional on the number of layers. Nevertheless, the size advantage of exporters is clearly larger across firms with more management layers. These figures look very similar after we control for time and industry fixed effects. The distributions of hours employed also exhibits similar shifts to the right for exporters with the difference growing larger for firms with more layers.

The comparison is not as clear when we compare the distribution of wages across exporters and non-exporters with a given number of layers. Exporters do tend to have a distribution of average hourly wage slightly shifted to the right, but the differences are small, and if anything,

\footnotetext{
${ }^{8}$ Part of our data is used in Eaton, et al. (2011b) to study the exporting behavior of firms. As a result, some of these facts for France are known from their paper. However, they have no results on layers or firm reorganization conditional on changing or keeping constant the number of layers.
} 
Figure 1: Value added distribution by number of layers and export status
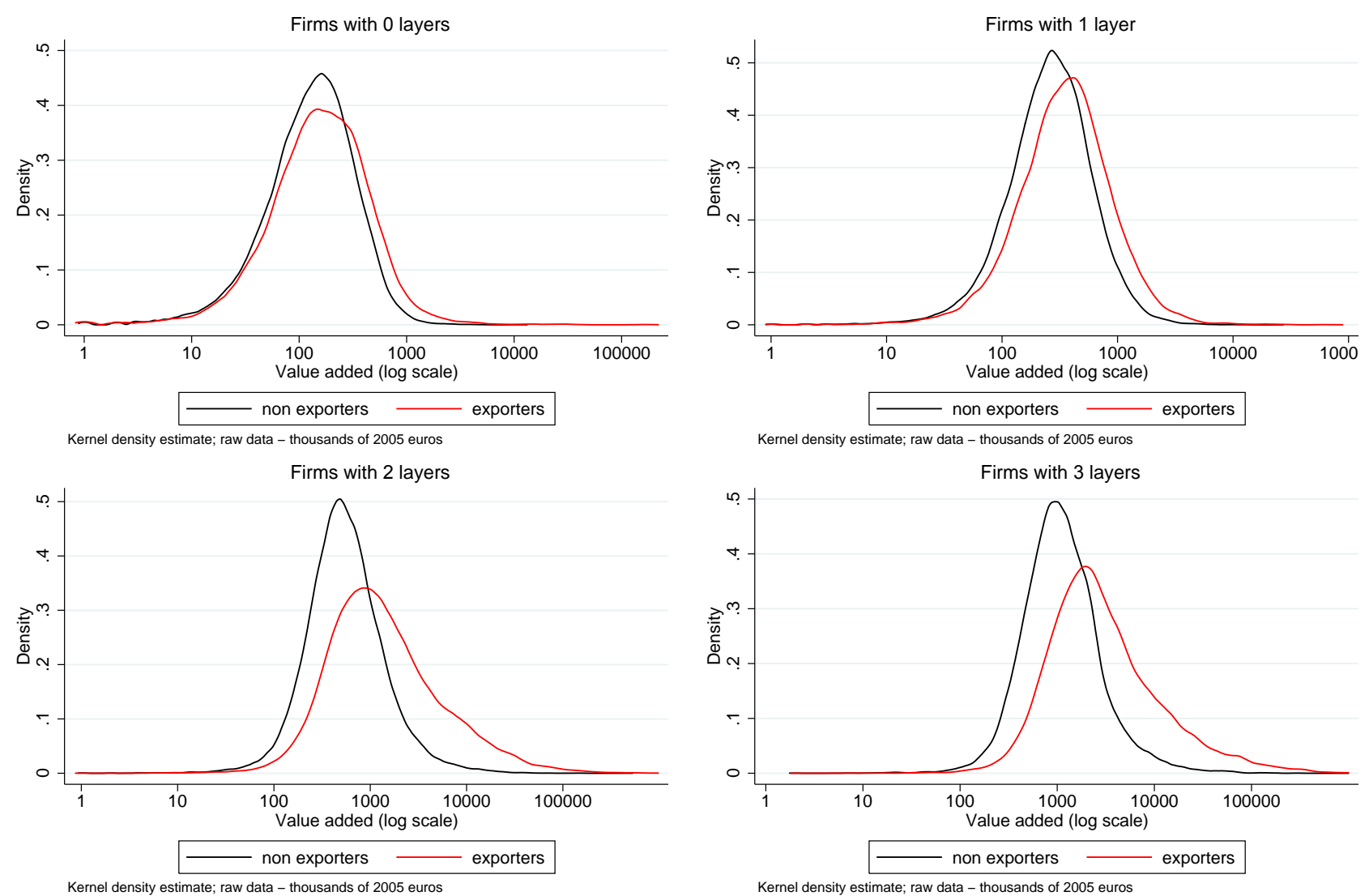
more pronounced for firms with less layers. Clearly, the fact that the average hourly wage combines employees with different skills and different roles in the organization that earn very different hourly wages, makes this comparison not particularly informative. As it is, the analysis combines the average wage of the CEO and the janitor. The theory of the organization of the firm outlined above can help us unpack these average effects. In fact, this theory tells us that exporters should pay more to the top layers, but less to the bottom ones. These two implications cancel each other out, at least partially, when we look at average wages.

Figure 2: Firm average hourly wage distribution by number of layers and export status
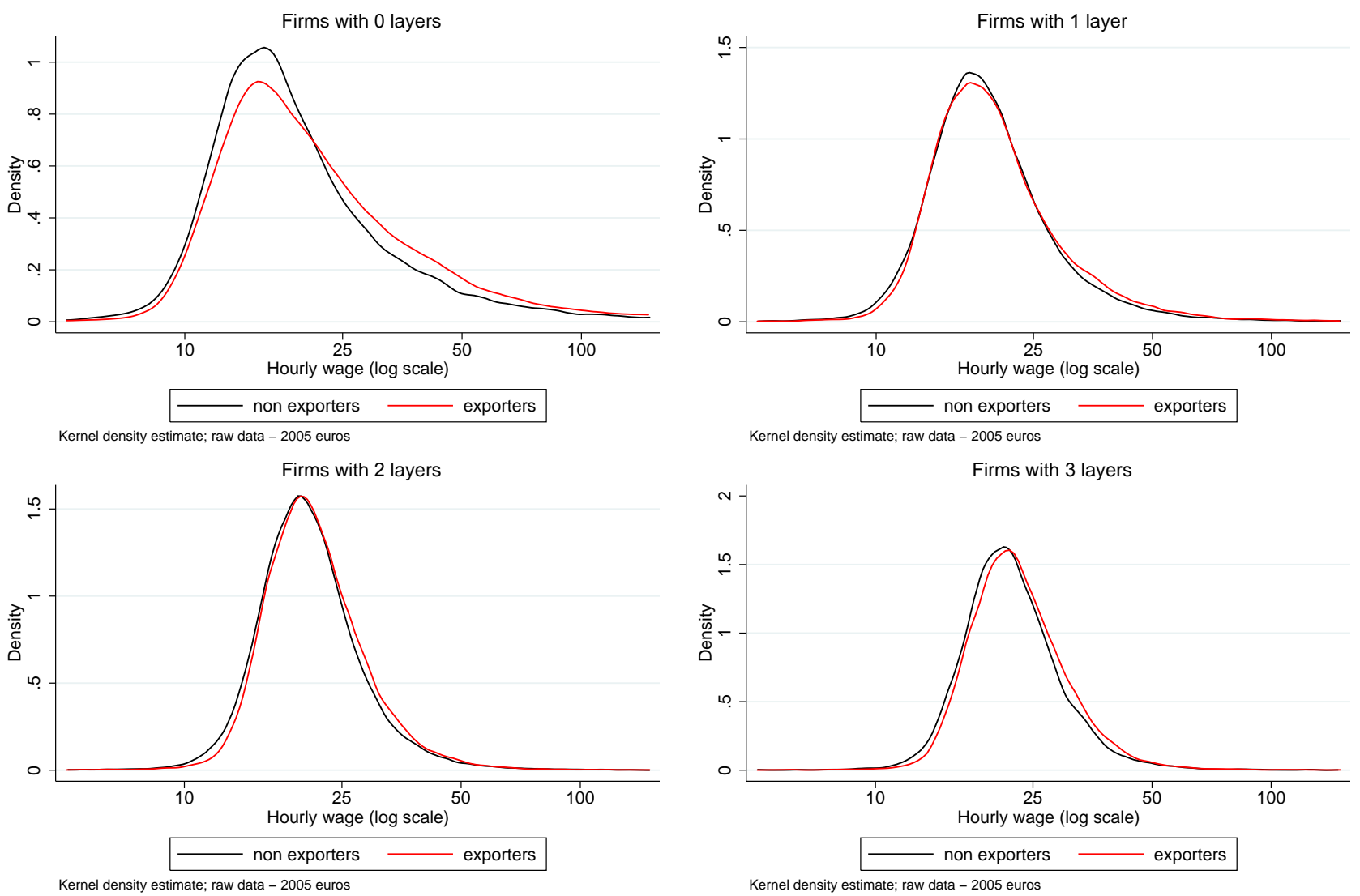

About $44 \%$ of the firms in our data export, and they account for slightly more than $83 \%$ of value added, with some variation across years. More relevant for our purposes is that the firms that export tend to have more layers. As Table 2 shows, of the firms with three layers of management, $66.7 \%$ of them export, while for firms with only workers, only $9.5 \%$ of them export.

Table 3 presents the composition of firms by number of layers. Out of all exporters, only $15.5 \%$ have only a layer of management, while $44.3 \%$ have two layers of management, and $35.5 \%$ have three. So there is substantial heterogeneity in the number of layers of exporters and non-exporters. Furthermore, most exporters have many layers, while most non-exporters have only one or two.

Taken together, the results in this section corroborate Implication 1 of the theory. We now turn to the behavior of firms over time. 
Table 2: Share of exporters by number of layers

\begin{tabular}{ccc}
\hline \# of layers & Unweighted & Weighted by $V A$ \\
\hline 0 & $9.5 \%$ & $15.9 \%$ \\
1 & $20.3 \%$ & $28.3 \%$ \\
2 & $45.0 \%$ & $81.7 \%$ \\
3 & $66.7 \%$ & $92.2 \%$ \\
\hline \hline
\end{tabular}

Table 3: Composition of firms by number of layers

\begin{tabular}{ccc}
\hline \# of layers & Non-exporters & Exporters \\
\hline 0 & $25.2 \%$ & $4.7 \%$ \\
1 & $34.4 \%$ & $15.5 \%$ \\
2 & $30.5 \%$ & $44.3 \%$ \\
3 & $10 \%$ & $35.5 \%$ \\
\hline Total & $100 \%$ & $100 \%$ \\
\hline \hline
\end{tabular}

\subsection{New Exporters}

We now focus on firms that become exporters during the period in our sample: new exporters. New exporters are more likely to add layers than non-exporters. Table 4 shows that the probability of adding one or more layers for new exporters is significantly higher than for non-exporters, regardless of the initial count of layers. The probability of keeping the same number of layers goes down if the firm has zero or one layer of management, while the probability of keeping the same number of layers increases for firms with two or three layers. Given that firms with three layers cannot add layers, this is natural. We conclude from this evidence that new exporters tend to add layers, consistent with the fact that they grow as a result. Of course, there are some that also drop layers, but there are fewer of those firms than those that do not start to export. Table 5 shows that firms that exit the export market are also more likely to drop layers than exporters that do not exit. So the effect is symmetric: firms that enter the export market are more likely to add layers and firms that exit are more likely to drop layers. These two tables corroborate our Implication $2 \mathrm{a}$.

Table 4: Layer transitions for new exporters relative to non-exporters

\begin{tabular}{cccccc}
\hline & \multicolumn{4}{c}{ \# of layers at $t+1$} \\
\cline { 3 - 6 } & & 0 & 1 & 2 & 3 \\
\cline { 2 - 5 } \# of layers & 1 & -10.84 & 7.84 & 2.50 & 0.50 \\
at $t$ & 2 & -0.15 & -2.91 & 6.40 & 0.67 \\
& 3 & -0.20 & -5.75 & 4.34 & 2.32 \\
\hline \hline
\end{tabular}

All significant at $1 \%$.

In fact, the new exporters that add layers expand on average much more than the ones that do not reorganize. Table 6 shows the changes in hours, normalized hours, value added and average 
Table 5: Layer transitions for exporters exiting relative to exporters staying

\begin{tabular}{crcccc}
\hline & \multicolumn{4}{c}{ \# of layers at $t+1$} \\
\cline { 3 - 6 } & & 0 & 1 & 2 & 3 \\
\cline { 3 - 6 } \# of layers & 1 & $3.51^{* * *}$ & -1.84 & $-2.19^{* * *}$ & $-0.47^{* * *}$ \\
at $t$ & 2 & $0.83^{* * * *}$ & 0.30 & $-3.14^{* * *}$ & $-0.45^{* *}$ \\
& 3 & $0.14^{* * *}$ & $1.60^{* * *}$ & $-3.73^{* * *}$ & $-3.60^{* * *}$ \\
& 3 & $5.46^{* * *}$ & $-7.30^{* * *}$ \\
\hline \hline
\end{tabular}

** significant at $5 \%, * * *$ significant at $1 \%$.

wages for all new exporters, the ones that add layers, and the ones that do not change $L$. We present results when we detrend using trends for all firms in the economy (not only new exporters, of course). Firms that start exporting increase value added on average by $3.6 \%$. The ones that add layers increase value added by much more, $11.7 \%$, while the ones that do not change layers increase value added by only $3.1 \%$. We find similar numbers for hours and normalized hours. Namely, new exporters that add layers expand much more than firms that do not add layers.

Table 6: Behavior of firms that enter the export market

\begin{tabular}{llll}
\hline & \multicolumn{1}{c}{ All } & Increase $L$ & No change in $L$ \\
\cline { 2 - 4 }$d \ln$ total hours & $0.031^{* * *}$ & $0.161^{* * *}$ & $0.019^{* * *}$ \\
- detrended & $0.046^{* * *}$ & $0.176^{* * *}$ & $0.034^{* * *}$ \\
$d \ln \sum_{\ell=0}^{L} n_{L}^{\ell}$ & 0.012 & $1.233^{* * *}$ & $0.014^{* *}$ \\
- detrended & $0.024^{* *}$ & $1.244^{* * *}$ & $0.025^{* * *}$ \\
$d \ln V A$ & $0.036^{* * *}$ & $0.117^{* * *}$ & $0.031^{* * *}$ \\
- detrended & $0.044^{* * *}$ & $0.125^{* * *}$ & $0.038^{* * *}$ \\
$d \ln$ avg wage & $0.004^{*}$ & $-0.025^{* * *}$ & $0.010^{* * *}$ \\
- detrended & $-0.015^{* * *}$ & $-0.045^{* * *}$ & $-0.009^{* * *}$ \\
- common layers & 0.004 & $-0.143^{* * *}$ & $0.010^{* * *}$ \\
- - detrended & $-0.016^{* * *}$ & $-0.163^{* * *}$ & $-0.010^{* * *}$ \\
\hline \hline \% firms & 100 & 14.17 & 71.81 \\
$\% V A$ change & 100 & 46.59 & 49.49 \\
\hline \hline ** significant at $5 \%,{ }^{* * *}$ significant at $1 \%$. &
\end{tabular}

Now let's look at wages. After detrending, new exporters pay wages similar to those paid before; so do firms that do not change layers. In contrast, firms that increase layers decrease wages by a significant $4.5 \%$. Perhaps more relevant is that this average change masks a composition effect between the new top manager and pre-existing layers. When we focus on wages of employees in pre-existing layers, we find that wages fall by $14.3 \%$ in firms that add layers ( $16.3 \%$ if we detrend), while they increase $1 \%$ in firms that do not change layers (although the change is insignificant when we detrend).

The results paint a picture consistent with the one presented in the previous section. New exporters that reorganize reduce wages in pre-existing layers. Furthermore, these are the new exporters that actually expand significantly. The firms that add layers account for $14.17 \%$ of new 
exporters and $46.59 \%$ of the total increase in value added by new exporters. In sum, many firms expand little when they become exporters; these firms increase the salaries of all their employees. Some firms expand a lot when they start to export. They reorganize, add layers, and pay lower wages to employees in the pre-existing layers and higher than average wages to the new top manager.

We now proceed to verify that these results hold layer by layer. We look first at firms that do not add layers. We estimate the regression

$$
d \ln \tilde{n}_{L i t}^{\ell}=\beta_{L}^{\ell} d \ln \widetilde{V A}_{i t}+\varepsilon_{i t}
$$

where $i$ denotes a firm, $L$ denotes the total number of layers, $t$ denotes time and $d$ denotes a yearly time difference. $\tilde{n}_{L i t}^{\ell}$ represents normalized hours, and $\widetilde{V A}_{i t}$ is the value added of a firm that stays at $L$ layers for two consecutive years; we have removed from both variables the economy-wide trend. The only difference is that now we use only firms that either start to export or stop exporting in the year in which we measure the change in normalized hours. The results for $\beta_{L}^{\ell}$ are presented in Table 7. Many of these estimates are not significant. The ones that are, are positive as predicted by the theory. As we showed using Table 5, the firms that do not add layers expand very little, so it is hard to estimate $\beta_{L}^{\ell}$ precisely enough to have significant results.

Table 7: Firms that change export status and do not change layers

\begin{tabular}{cccccc}
\hline \# of layers & Layer & $\beta_{L}^{\ell}$ & s.e. & p-value & obs \\
\hline 1 & 0 & 0.027 & 0.04 & 0.45 & 5,178 \\
2 & 0 & 0.026 & 0.03 & 0.33 & 9,434 \\
2 & 1 & -0.010 & 0.03 & 0.73 & 9,434 \\
3 & 0 & 0.117 & 0.04 & 0.01 & 4,789 \\
3 & 1 & 0.103 & 0.05 & 0.03 & 4,789 \\
3 & 2 & 0.066 & 0.05 & 0.17 & 4,789 \\
\hline \hline
\end{tabular}

We estimate a parallel equation for wages, for the sample of firms that change export status:

$$
d \ln \tilde{w}_{L i t}^{\ell}=\gamma_{L}^{\ell} d \ln \widetilde{V A}_{i t}+\varepsilon_{i t}
$$

where $\tilde{w}_{L i t}^{\ell}$ is the detrended change in layer-level wages. Results are presented in Table 8 . Now the estimates are much more significant and robust. All the values of $\gamma_{L}^{\ell}$ are positive and significant and they tend to increase with $\ell$ given $L$. The ranking of the elasticities is not always significant, but it is in most cases, and when it is, it corresponds to the one predicted by the theory. Namely, the wage of the higher-level managers expands proportionally more than that of the lower-level ones. Hence, Implication $2 \mathrm{~b}$ is also corroborated by the evidence.

The final prediction of the theory to contrast with our data is Implication 2c, which states that new exporters that add layers decrease $w_{L}^{\ell}$ and increase $n_{L}^{\ell}$ at all $\ell$. We have already argued in the previous section that firms that add layers decrease wages and increase hours at all layers, and Table 4 shows that new exporters tend to add layers. So it is natural to expect that in fact the 
Table 8: Firms that change export status and do not change layers

\begin{tabular}{cccccc}
\hline \# of layers & Layer & $\gamma_{L}^{\ell}$ & s.e. & p-value & obs \\
\hline 0 & 0 & 0.065 & 0.02 & 0.00 & 2,064 \\
1 & 0 & 0.072 & 0.02 & 0.00 & 5,178 \\
1 & 1 & 0.087 & 0.02 & 0.00 & 5,178 \\
2 & 0 & 0.122 & 0.02 & 0.00 & 9,434 \\
2 & 1 & 0.143 & 0.02 & 0.00 & 9,434 \\
2 & 2 & 0.152 & 0.02 & 0.00 & 9,434 \\
3 & 0 & 0.194 & 0.03 & 0.00 & 4,789 \\
3 & 1 & 0.202 & 0.03 & 0.00 & 4,789 \\
3 & 2 & 0.204 & 0.03 & 0.00 & 4,789 \\
3 & 3 & 0.260 & 0.04 & 0.00 & 4,789 \\
\hline \hline
\end{tabular}

predictions of the theory will be corroborated by the data.

Table 9 presents the average log change in the number of hours for all transitions and all layers. The table uses the sample of firms that enter the export market and add layers and firms that exit the export market and drop layers. The results establish that, for all transitions and layers, firms that add layers increase the number of hours, while firms that drop layers decrease them.

The next step is to look at wages. Again, we study the change in average log wages for all transitions and layers for the sample of new exporters that add layers and firms that exit the export market and drop layers. The results are displayed in Table 10. The prediction in Implication 2c is broadly corroborated by the data (although the change in log wages for the case in which we do not have many observations is not significant). New exporters that add layers decrease wages and the firms that exit the export market and drop layers increase wages. As we show in Table 4, new exporters tend to add more layers than non-exporters. Similarly, firms that exit the export market tend to drop more layers than exporters.

So, exporters tend to reduce wages as a result of adding layers. To consider an example, a new exporter that had one layer of management and added another as a result of its decision to start exporting reduces the wages of its workers in layer zero by $8.2 \%$, and the wage of managers in layer one declines by 30\%. In contrast, as Table 11 (discussed below) shows, the newly hired second layer manager earns $90.2 \%$ more than the average wage in the firm before the change.

The result should change our view on the distribution of the gains from exporting. The view that new exporters pay higher wages is misleading. Most new exporters expand little and do not change their organization. They hire more hours and pay higher wages. The new exporters that expand substantially add layers of management. They hire substantially more workers but pay these workers less (since according to the theory they also know less). The new exporters that expand and add layers exhibit more dispersion in wages within the firm.

Table 11 separates the change in wages in the firm in the contribution to the average of the new 
Table 9: Change in normalized hours for firms that transition and change export status

\begin{tabular}{ccccccl}
\hline \multicolumn{2}{c}{$\begin{array}{c}\text { \# of layers } \\
\text { Before }\end{array}$} & Lfter & & & & \\
\hline 0 & 1 & 0 & 1.476 & 0.10 & 0.00 & 347 \\
0 & 2 & 0 & 1.786 & 0.24 & 0.00 & 62 \\
0 & 3 & 0 & 2.815 & 0.31 & 0.00 & 9 \\
1 & 0 & 0 & -1.614 & 0.08 & 0.00 & 434 \\
1 & 2 & 0 & 0.748 & 0.05 & 0.00 & 843 \\
1 & 2 & 1 & 0.612 & 0.05 & 0.00 & 843 \\
1 & 3 & 0 & 1.045 & 0.18 & 0.00 & 62 \\
1 & 3 & 1 & 0.965 & 0.18 & 0.00 & 62 \\
2 & 0 & 0 & -1.952 & 0.22 & 0.00 & 85 \\
2 & 1 & 0 & -0.734 & 0.05 & 0.00 & 949 \\
2 & 1 & 1 & -0.558 & 0.05 & 0.00 & 949 \\
2 & 3 & 0 & 1.073 & 0.06 & 0.00 & 676 \\
2 & 3 & 1 & 1.008 & 0.06 & 0.00 & 676 \\
2 & 3 & 2 & 0.822 & 0.07 & 0.00 & 676 \\
3 & 0 & 0 & -2.713 & 0.46 & 0.00 & 8 \\
3 & 1 & 0 & -1.125 & 0.15 & 0.00 & 94 \\
3 & 1 & 1 & -0.911 & 0.16 & 0.00 & 94 \\
3 & 2 & 0 & -1.248 & 0.05 & 0.00 & 860 \\
3 & 2 & 1 & -1.170 & 0.06 & 0.00 & 860 \\
3 & 2 & 2 & -1.042 & 0.06 & 0.00 & 860 \\
\hline \hline
\end{tabular}


Table 10: Change in wages for firms that transition and change export status

\begin{tabular}{|c|c|c|c|c|c|c|}
\hline \multicolumn{2}{|c|}{ \# of layers } & \multirow[t]{2}{*}{ Layer } & \multirow[t]{2}{*}{ Change } & \multirow[t]{2}{*}{ s.e. } & \multirow[t]{2}{*}{ p-value } & \multirow[t]{2}{*}{ obs } \\
\hline Before & After & & & & & \\
\hline 0 & 1 & 0 & -0.156 & 0.02 & 0.00 & 347 \\
\hline 0 & 2 & 0 & -0.697 & 0.14 & 0.00 & 62 \\
\hline 0 & 3 & 0 & -0.906 & 0.48 & 0.10 & 9 \\
\hline 1 & 0 & 0 & 0.221 & 0.03 & 0.00 & 434 \\
\hline 1 & 2 & 0 & -0.082 & 0.01 & 0.00 & 843 \\
\hline 1 & 2 & 1 & -0.307 & 0.02 & 0.00 & 843 \\
\hline 1 & 3 & 0 & -0.215 & 0.09 & 0.01 & 62 \\
\hline 1 & 3 & 1 & -0.434 & 0.09 & 0.00 & 62 \\
\hline 2 & 0 & 0 & 0.439 & 0.09 & 0.00 & 85 \\
\hline 2 & 1 & 0 & 0.053 & 0.01 & 0.00 & 949 \\
\hline 2 & 1 & 1 & 0.237 & 0.02 & 0.00 & 949 \\
\hline 2 & 3 & 0 & -0.039 & 0.01 & 0.67 & 676 \\
\hline 2 & 3 & 1 & -0.082 & 0.02 & 0.00 & 676 \\
\hline 2 & 3 & 2 & -0.217 & 0.02 & 0.00 & 676 \\
\hline 3 & 0 & 0 & 1.053 & 0.60 & 0.12 & 8 \\
\hline 3 & 1 & 0 & 0.175 & 0.07 & 0.01 & 94 \\
\hline 3 & 1 & 1 & 0.430 & 0.07 & 0.00 & 94 \\
\hline 3 & 2 & 0 & 0.043 & 0.01 & 0.00 & 860 \\
\hline 3 & 2 & 1 & 0.061 & 0.01 & 0.00 & 860 \\
\hline 3 & 2 & 2 & 0.166 & 0.02 & 0.00 & 860 \\
\hline
\end{tabular}

Table 11: Decomposition of total log change in average wages

\begin{tabular}{|c|c|c|c|c|c|c|c|}
\hline \multicolumn{4}{|c|}{$\bar{w}_{L^{\prime} i t}^{\ell \leq L} / \bar{w}_{L i t}$} & \multicolumn{4}{|c|}{$w_{L^{\prime} i t}^{L^{\prime}} / \bar{w}_{L i t}$} \\
\hline From/to & 1 & 2 & 3 & From/to & 1 & 2 & 3 \\
\hline 0 & $\begin{array}{c}0.935^{* *} \\
(346)\end{array}$ & $\begin{array}{c}0.734^{* *} \\
(61)\end{array}$ & $\begin{array}{c}0.706^{* *} \\
(9)\end{array}$ & 0 & $\begin{array}{l}1.454^{* *} \\
(346)\end{array}$ & $\begin{array}{c}1.331^{* *} \\
(62)\end{array}$ & $\begin{array}{c}1.666^{*} \\
(9)\end{array}$ \\
\hline 1 & & $\begin{array}{l}0.912^{* *} \\
(842)\end{array}$ & $\begin{array}{c}0.838^{* *} \\
(60)\end{array}$ & 1 & & $\frac{1.902^{* *}}{(841)}$ & $\begin{array}{c}2.015^{\text {** }} \\
(62)\end{array}$ \\
\hline 2 & & & $\begin{array}{c}0.975^{* *} \\
(675)\end{array}$ & 2 & & & $\begin{array}{c}7.336^{*} \\
(675)\end{array}$ \\
\hline \multicolumn{4}{|c|}{$s$} & \multicolumn{4}{|c|}{$d \ln \bar{w}_{L i t}$} \\
\hline From/to & 1 & 2 & 3 & From/to & 1 & 2 & 3 \\
\hline 0 & $\begin{array}{c}0.732^{* *} \\
(346)\end{array}$ & $\begin{array}{c}0.618^{* *} \\
(62)\end{array}$ & $\begin{array}{l}0.581^{* *} \\
(9)\end{array}$ & 0 & $\begin{array}{c}-0.014 \\
(346)\end{array}$ & $\begin{array}{c}-0.454^{* *} \\
(61)\end{array}$ & $\begin{array}{c}-0.184 \\
(8)\end{array}$ \\
\hline 1 & & $\begin{array}{c}0.856^{* *} \\
(843)\end{array}$ & ${ }_{(62)}^{0.775^{* *}}$ & 1 & & $-0.036^{* *}$ & $\begin{array}{c}-0.070 \\
(61)\end{array}$ \\
\hline 2 & & & $\underset{(676)}{0.946^{* *}}$ & 2 & & & $\begin{array}{c}-0.023 \\
(675)\end{array}$ \\
\hline
\end{tabular}

All results from trimmed sample at $0.05 \%$. ${ }^{*}$ significant at $5 \%,{ }^{* *}$ at $1 \%$. Number of obs. in parenthesis. 
top manager and the change in the wage of the pre-existing layers. The top left panel shows that the average wage of all existing layers decreases as firms add layers (and we know from Table 10 that it decreased for each layer individually). The top right panel shows the wage of the new top manager relative to the mean wage of the firm before the change. Clearly, wage dispersion in the firm increases substantially when it starts to export and adds layers.

We end this section with a graphical representation of the change in firms as they become exporters. Figures 3 to 5 show how the typical organization of firms change when they enter or exit the export market: in each figure, the first row in each graph represents the old and new organization when the firm adds layers and starts to export, while the second row represents a current exporter which leaves the export market. ${ }^{9}$ Perhaps the most striking observation coming out of Figures 3 to 5 is how large the changes are as firms actively manage their organization. This is in stark contrast to the very small changes for those firms not reorganizing, as reported in Tables 7 and 8. Hopefully, these figures are convincing in showing that new exporters expand by adding layers, adding employment, and reducing wages. The reduction in wages challenges, as far as we know, all theories of trade that do not add explicit organizational choices.
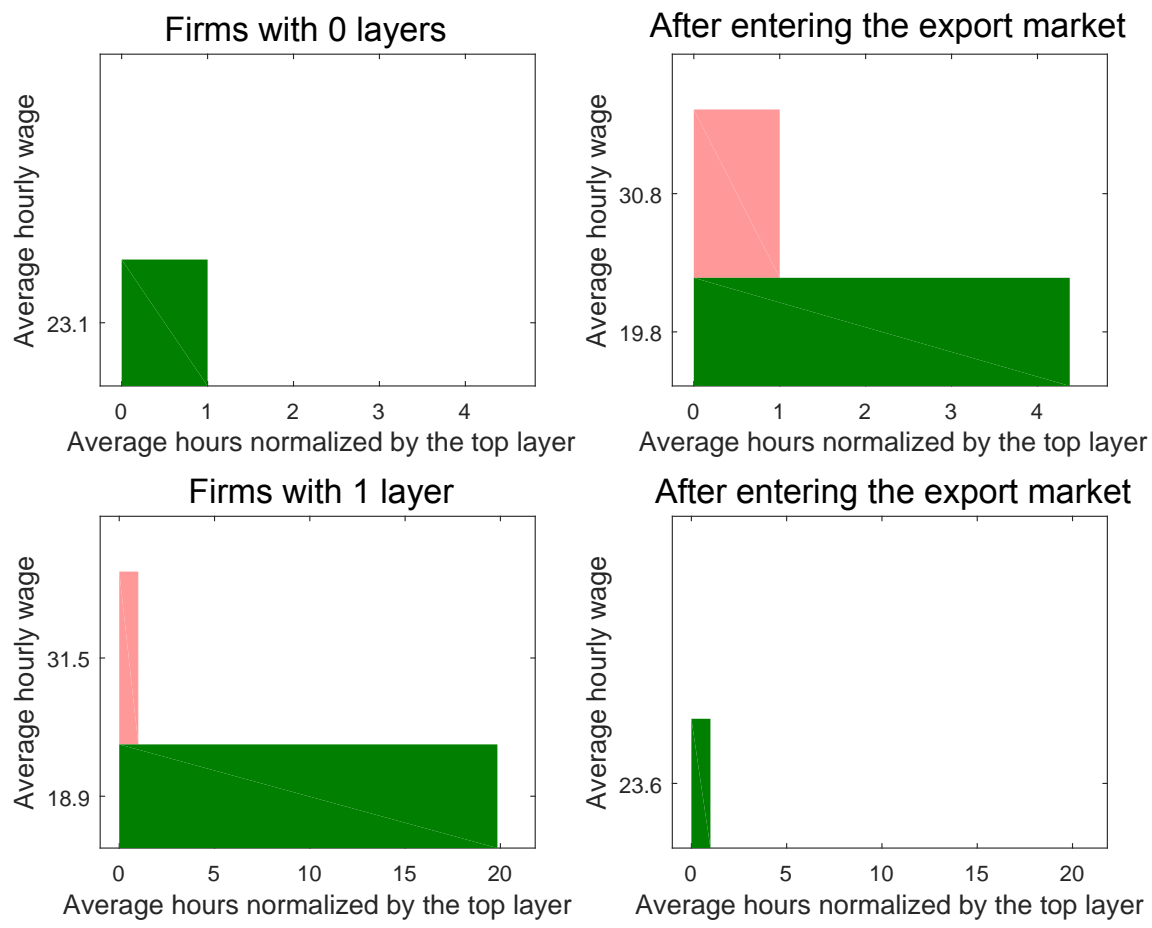

Figure 3: Representative transitions from and to $L=0$

\footnotetext{
${ }^{9}$ To estimate the representative hierarchies before a transition, we compute the average number of normalized hours and wage only in the subset of firms with $L$ layers that will enter the export market and have $L+1$ layers the following period. To estimate the representative hierarchy after the transition, we use the estimated log changes for firms entering the export market from Tables 9 and 10. For transitions one layer up, the change in the hourly wage for the top layer after the transition is estimated as the average log change in the wage of the top layer $\left(\ln w_{L+1, t+1}^{L+1}-\ln w_{L, t}^{L}\right)$.
} 

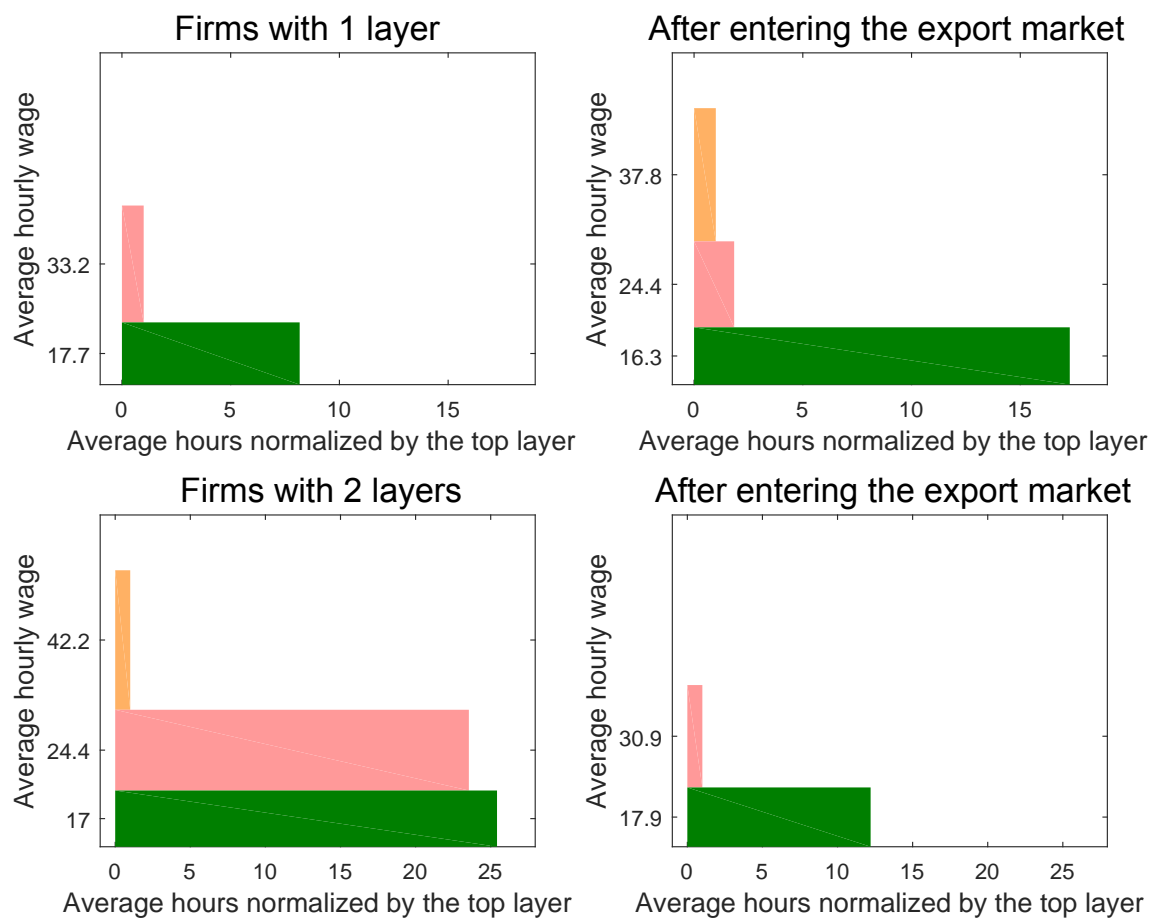

After entering the export market

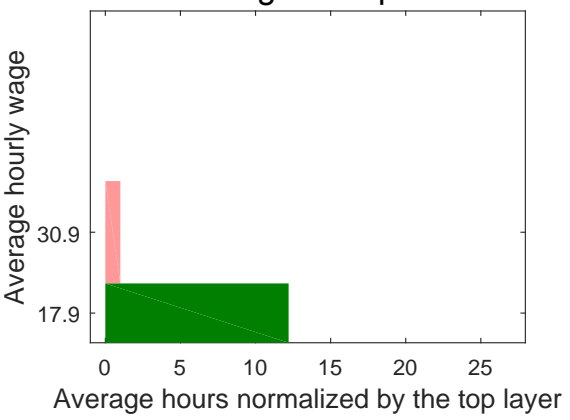

Figure 4: Representative transitions from and to $L=1$
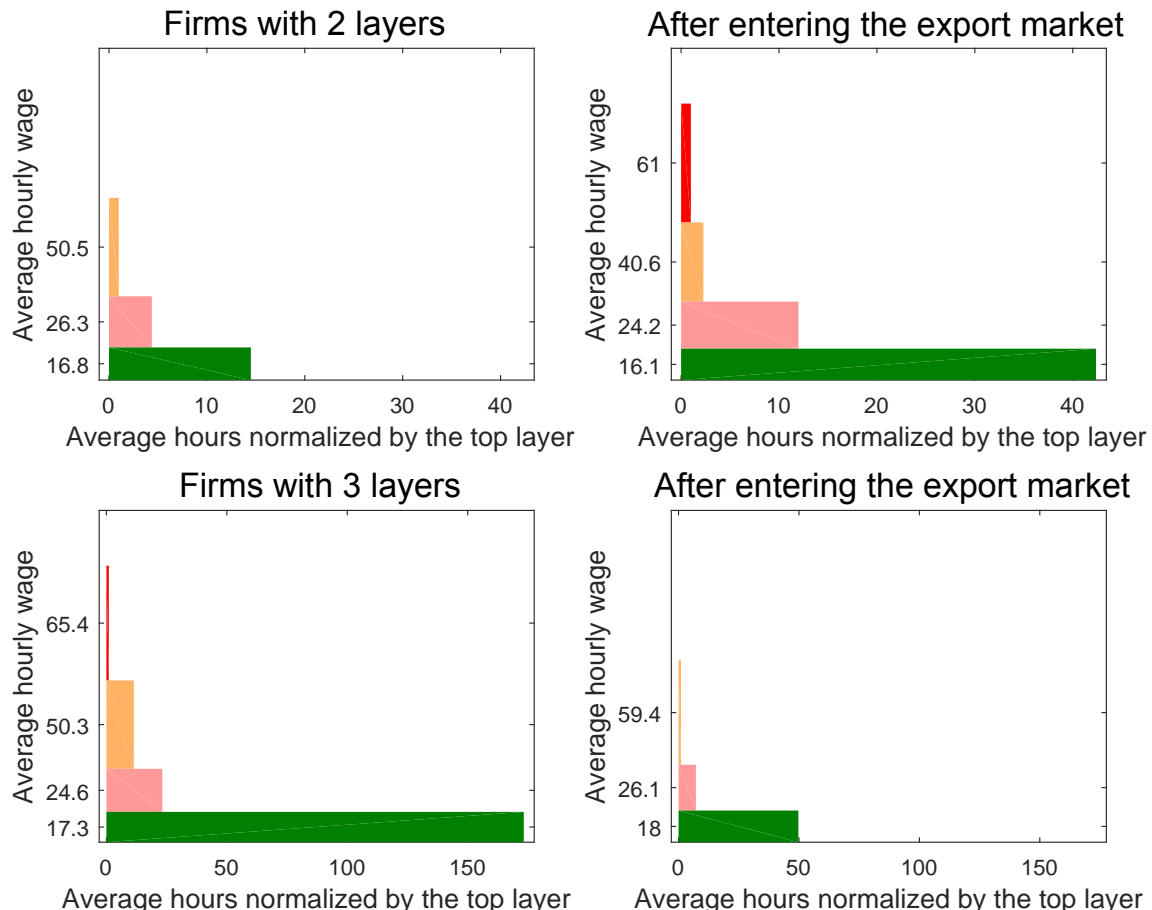

Figure 5: Representative transitions from and to $L=2$ 


\section{How do Firms Change the Average Wage in a Layer?}

Table 12 shows that for firms that change their export status (either entering or leaving the export market without adding layers), the only significant adjustments occur via changes in formal education, and especially at lower layers.

Table 12: Elasticity of Knowledge with Value Added for Firms That Start or Stop Exporting and Do Not Change $L$

\begin{tabular}{ccclcll}
\hline \# of layers & Layer & Experience & p-Value & Education & p-Value & obs \\
\hline 0 & 0 & 0.003 & 0.745 & 0.006 & 0.023 & 2,062 \\
1 & 0 & -0.029 & 0.013 & 0.006 & 0.007 & 5,172 \\
1 & 1 & -0.006 & 0.628 & 0.007 & 0.002 & 5,172 \\
2 & 0 & -0.008 & 0.356 & 0.004 & 0.007 & 9,422 \\
2 & 1 & 0.008 & 0.537 & 0.004 & 0.015 & 9,422 \\
2 & 2 & 0.017 & 0.073 & 0.000 & 0.892 & 9,422 \\
3 & 0 & -0.008 & 0.437 & 0.003 & 0.170 & 4,783 \\
3 & 1 & 0.008 & 0.602 & 0.000 & 0.884 & 4,783 \\
3 & 2 & 0.002 & 0.871 & -0.001 & 0.773 & 4,783 \\
3 & 3 & 0.008 & 0.556 & -0.002 & 0.678 & 4,783 \\
\hline \hline
\end{tabular}

Table 13 shows that when a change in the export status is accompanied by a reorganization, firms tend to mostly act upon experience, while formal education is almost never significant. These patterns are consistent (although somewhat more noisy) with our findings for the general population of firms.

\section{Exogenous Export Demand Shocks and Reorganization}

In this section, we explore a more causal relation between reorganization and layer-level outcomes. In particular, we exploit variation in firm-level exports induced exogenously by country variations in real exchange rate as a "foreign demand shock". In the theory, firms close to the reorganization threshold should add a layer following a demand shock large enough; such reorganization will trigger changes in layer-level outcomes.

To compute plausibly exogenous firm-level demand shocks, we exploit pre-sample variation in the destination composition of exports, in conjunction with real exchange rate variation across countries. For each firm, we observe the shares of export to all its destinations in $2002, s_{i d}$; we then build the following measures of exposure for firm $i$ at time $t$ :

$$
W_{i t}^{(k)}=\sum_{d} s_{i d} w_{d t}^{(k)}
$$

where $w_{i t}^{(k)}$ is either the bilateral real exchange rate ${ }^{10}$ between France and destination $d$ in year $t$

\footnotetext{
${ }^{10}$ We have defined the real exchange rate so that an increase corresponds to a depreciation, and should hence induce
} 
Table 13: Elasticity of Knowledge with Value Added for Firms That Start Exporting and Increase $L$, or Stop Exporting and Decrease $L$

\begin{tabular}{|c|c|c|c|c|c|c|c|}
\hline \multicolumn{2}{|c|}{ \# of layers } & \multirow[t]{2}{*}{ Layer } & \multirow[t]{2}{*}{ Experience } & \multirow[t]{2}{*}{ p-Value } & \multirow[t]{2}{*}{ Education } & \multirow[t]{2}{*}{ p-Value } & \multirow[t]{2}{*}{ obs } \\
\hline Before & After & & & & & & \\
\hline 0 & 1 & 0 & -0.161 & 0.000 & 0.004 & 0.413 & 346 \\
\hline 0 & 2 & 0 & -0.148 & 0.055 & -0.014 & 0.174 & 62 \\
\hline 0 & 3 & 0 & -0.324 & 0.081 & 0.054 & 0.132 & 9 \\
\hline 1 & 0 & 0 & 0.061 & 0.004 & 0.006 & 0.132 & 433 \\
\hline 1 & 2 & 0 & -0.030 & 0.017 & 0.000 & 0.817 & 841 \\
\hline 1 & 2 & 1 & -0.190 & 0.000 & 0.001 & 0.861 & 841 \\
\hline 1 & 3 & 0 & -0.049 & 0.250 & 0.006 & 0.652 & 62 \\
\hline 1 & 3 & 1 & -0.208 & 0.010 & 0.000 & 0.990 & 62 \\
\hline 2 & 0 & 0 & 0.044 & 0.513 & 0.004 & 0.667 & 85 \\
\hline 2 & 1 & 0 & 0.036 & 0.002 & 0.003 & 0.103 & 945 \\
\hline 2 & 1 & 1 & 0.170 & 0.000 & -0.007 & 0.039 & 945 \\
\hline 2 & 3 & 0 & -0.007 & 0.510 & 0.002 & 0.166 & 675 \\
\hline 2 & 3 & 1 & -0.036 & 0.020 & 0.001 & 0.739 & 675 \\
\hline 2 & 3 & 2 & -0.206 & 0.000 & 0.026 & 0.000 & 675 \\
\hline 3 & 0 & 0 & 0.158 & 0.244 & 0.032 & 0.227 & 8 \\
\hline 3 & 1 & 0 & 0.091 & 0.052 & -0.004 & 0.591 & 94 \\
\hline 3 & 1 & 1 & 0.189 & 0.007 & -0.016 & 0.163 & 94 \\
\hline 3 & 2 & 0 & 0.028 & 0.002 & -0.001 & 0.391 & 860 \\
\hline 3 & 2 & 1 & 0.013 & 0.284 & 0.002 & 0.356 & 860 \\
\hline 3 & 2 & 2 & 0.111 & 0.000 & -0.018 & 0.000 & 860 \\
\hline
\end{tabular}


(denoted with $k=1$ ), or the yearly change in the same bilateral real exchange rate between $t$ and $t+1$ (denoted with $k=2$ ).

We start by estimating ${ }^{11}$ the following model that relates export shocks to the probability of changing layers:

$$
\left\{\begin{array}{rc}
d \log X_{L i t}= & c_{L}^{0}+\omega_{L}^{\prime} W_{L i t}+\nu_{L}^{\prime} V_{L i t}+\varepsilon_{\text {Lit }}^{0} \\
\operatorname{Pr}\left\{\text { dLayer }_{\text {Lit }}=N\right\}= & \left\{\alpha_{L, N-1} \leq c_{L}^{1}+\xi_{L} \cdot d \log X_{L i t}+\right. \\
& \left.+\eta_{L}^{\prime} V_{L i t}+\varepsilon_{L i t}^{1} \leq \alpha_{L, N}\right\}
\end{array}\right.
$$

In this notation, $i$ denotes a firm, $t$ denotes time, and $L$ denotes the number of layers firm $i$ has at the beginning of time $t .{ }^{12} c^{j}$ and $\varepsilon_{L i t}^{j}$ for $j=0,1$ are constants and stochastic i.i.d. error terms, respectively.

The first equation is a linear regression; it describes the change over time in log exports as a function of exposure to real exchange rate variations $W_{\text {Lit }}=\left\{W_{L i t}^{(1)}, W_{\text {Lit }}^{(2)}\right\}$, and a vector $V_{\text {Lit }}$ of controls: year dummies and $\log$ value added of firm $i$ with $L$ layers at the beginning of the year (to proxy for how close the firm is to the threshold).

The second equation is an ordered probit: it models the probability of any change in the number of layers as a function of the firm change in exports and the same set of controls (the parameters $\alpha_{L, N}$ are the standard thresholds for the latent variable).

We focus on the set of firms who export throughout the sample period. We estimate this model separately for all firms with initial number of layers $L$.

Table 14 reports estimates for the coefficient $\xi_{L}$ in eq. (11.1). ${ }^{13}$ Increases in exports induced by variations in the real exchange rate significantly affect the probability of reorganizing the firm. The last column in the table shows the probability of adding one layer for firms at the $90^{\text {th }}$ percentile of value added implied by these coefficients, following a 10\% increase in export demand: for example, exporters with 1 layer at the $90^{\text {th }}$ percentile of size within the group have a $33.7 \%$ chance of reorganizing if they are hit by an exogenous $10 \%$ increase in export demand.

Table 14: Impact of Change in Export on dLayer $s_{\text {Lit }}$

\begin{tabular}{cccccc}
\hline \# of layers & $\xi_{L}$ & s.e. & p-value & obs & $\operatorname{Pr}\left\{\begin{array}{c}d \text { Layer }_{\text {Lit }}=+1 \mid \\
L, \text { V }_{\text {Lit }}=p_{90}(L)\end{array}\right\}$ \\
\hline 0 & 1.138 & 0.04 & 0.00 & 1,557 & 0.057 \\
1 & 0.649 & 0.27 & 0.02 & 7,337 & 0.337 \\
2 & 1.063 & 0.20 & 0.00 & 29,965 & 0.414 \\
3 & -0.193 & 0.36 & 0.59 & 28,816 & - \\
\hline \hline
\end{tabular}

To study how these demand shocks affect firm-level outcomes, we extend (11) and estimate the

an increase in exports.

${ }^{11}$ We use routines developed by Roodman (2011).

${ }^{12}$ In the notation, the number of layers $L$ is superfluous since it is uniquely identified by a firm and a time, i.e., $L=L(i, t)$. We keep $L$ explicit however since we will be performing separate estimates according to $L$.

${ }^{13}$ Table A1-1 in the Appendix reports the main coefficients in the second equation. While the contribution of individual regressors is noisily estimated, the joint model (11) is highly significant. 
four-equations model:

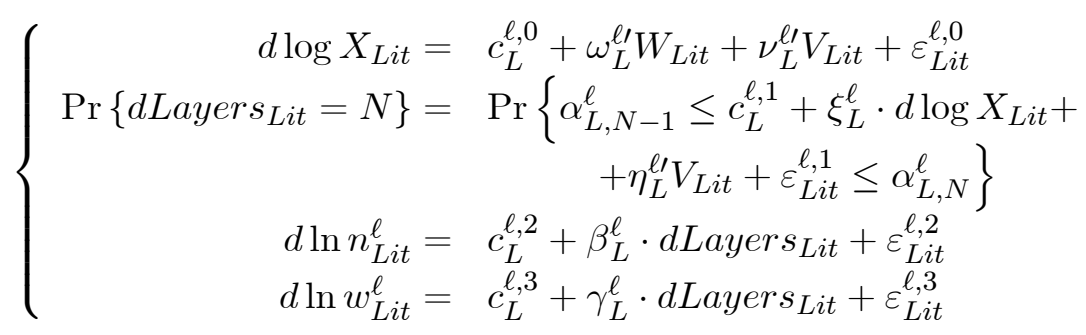

As above, $i$ denotes a firm, $t$ denotes time, and $L$ denotes the number of layers firm $i$ has at the beginning of time $t$; in addition, $\ell$ denotes the layer- $\ell$ outcome. $c^{\ell, j}$ and $\varepsilon_{L i t}^{\ell, j}$ for $j=0, \ldots, 3$ are constants and stochastic i.i.d. error terms, respectively.

Equations (12.1) and (12.2) are similar to (11.1) and (11.2) respectively, except that the coefficients are layer $\ell$-specific. We estimate this model separately for each initial number of layers $L$ and layer-level outcome $\ell$ : the estimation sample includes all firms that start with $L$ layers and have at least $\ell$ layers the following period. For example, one model would only look at all firms with $L=2$ layers initially, and study change in hours and wages at layer $\ell=1$, using all the firms that have at least 1 layer the next period.

The third and fourth equations in model (12) are linear regressions that relate the change in normalized hours and wages, respectively, at a given layer $\ell$ for a firm with $L$ layers initially, as a function of the change in layers.

Table 15 shows the estimates of the coefficients $\beta_{L}^{\ell}$ and $\gamma_{L}^{\ell} .{ }^{14}$ The coefficients can be read as the impact of adding 1 layer to the firm on the correspondent layer- $\ell$ outcome: for example, adding one layer in firms with $L=1$ layers implies a decrease in average wages of $100(1-\exp \{0.132\}) \%=$ $-14.1 \%$ in wages, but an increase of $100 \exp \{1.037\} \%=282 \%$ in the normalized number of hours in layer 0.

Overall, these results emphasize that firms react to shocks to their ability to trade by reorganizing in exactly the way we would expect from the logic in the theory. These reactions change their performance and in equilibrium have further repercussions both on trade and on other economic outcomes as emphasized by $\mathrm{CRH}$. Other papers have also explored some of these responses empirically in other countries and context. In the next section we describe these contributions.

\footnotetext{
${ }^{14}$ Note in this Table that when estimating outcomes in the top layers, observations drop somewhat. This happens because outcomes in the top layer are not observed when the firm drops it. This is also why layer-3 outcomes in firms with 3 layers cannot be estimated: the sample only includes firms with which do not change layers $\left(d L a y e r s_{L i t}=0\right)$, so that there is no variation on the RHS; morevoer, the left-hand side $d \ln \tilde{n}_{3 i t}^{3}$ also has no variation since normalized hours at the top are always 1 .

Table A1-2 in the Appendix reports the main coefficients in the first two equations. As above, the contribution of individual regressors is noisily estimated, but the joint model (12) is highly significant.
} 
Table 15: Impact of Change in Layers on Layer-Level Outcomes

\begin{tabular}{ccccccc}
\hline \# of layers & Layer & $\beta_{L}^{\ell}$ & $\mathrm{p}$-value & $\gamma_{L}^{\ell}$ & $\mathrm{p}$-value & obs \\
\hline 0 & 0 & 1.257 & 0.00 & -0.362 & 0.00 & 1,557 \\
1 & 0 & 1.037 & 0.00 & -0.132 & 0.00 & 7,337 \\
1 & 1 & 0.744 & 0.00 & -0.312 & 0.00 & 6,854 \\
2 & 0 & 1.851 & 0.00 & -0.091 & 0.00 & 29,965 \\
2 & 1 & 1.970 & 0.00 & -0.179 & 0.00 & 29,965 \\
2 & 2 & 1.929 & 0.00 & -0.208 & 0.00 & 27,886 \\
3 & 0 & 1.262 & 0.00 & -0.066 & 0.00 & 28,816 \\
3 & 1 & 1.299 & 0.00 & -0.092 & 0.00 & 28,816 \\
3 & 2 & 1.478 & 0.00 & -0.144 & 0.00 & 28,816 \\
\hline \hline
\end{tabular}

\section{Organizational Change and Trade in other Economic Context}

The starting point of this empirical agenda on organizations is that using changes in occupational categories to identify organizational structure and reorganizations is economically meaningful in that it is related to a variety of other firm characteristics like size, wages, employment, productivity, among others. CMRH presented the evidence for the case of France, and since then several studies document that mapping layers of management to occupations is meaningful across countries with very different labor market regulations and/or at very different stages of development. Moreover, some of these empirical studies find that reorganization not only has effects on firm level outcomes, but also aggregate implications for the economy.

A few studies have verified and reproduced the results in CMRH for different time periods and countries. For example, recent work by Bernini, Guillou, and Treibich, (2016) use French matchemployer employee data as in CMRH. They validate all of CMRH's results for a more recent period, the years 2009 to 2013. Also for France, Spanos (2016b) also shows that higher ability workers are employed in the higher layers of firms, and presents evidence of positive assortative matching between workers in the different layers. Tåg (2013) uses the Swedish Standard Classification of Occupations 1996 (SSYK) which is a national version of the International Standard Classification of Occupations (ISCO-88 (COM)). He finds that the empirical patterns in Sweden match the theoretical predictions of CRH (2012). In particular, he finds that firms in Sweden are hierarchal, i.e. higher layers have less workers and a higher mean wage than lower layers. Reorganizing by adding layers is accompanied with an increase in firm size and decrease in firm wages at pre-existing layers, while the reverse holds for firms that delayer.

In developing countries, Cruz, Bussolo and Iacovone (2016) study the Brazilian economy using the Classificao Brasileira de Ocupacao (CBO). Using this classification, they first document that firms are hierarchical in terms of hours and wages. Then, they find that in re-organized firms inequality of wages increases, as firms pay higher wages in added higher layers than in pre-existing ones. Also, and importantly for the main implications of the evidence in this paper, they document how the change in firms' organization is positively correlated with export performance. So the 
results we find in France are very much consistent with their results for Brazil.

In order to try to be more detailed on the identification of the effect of exporting on organizational change, Friedrich (2016) uses confidential data collected by Statistics Denmark to study the internal organization of Danish firms. He finds evidence for how trade affects wage inequality, focusing on changes in firm hierarchies. Its main contribution is that the paper identifies a causal effect of trade shocks on firm hierarchies and wage inequality. Namely, Friedrich (2016) shows that trade shocks do generate changes in the way firms organize production and as a result the way in which wage inequality changes inside the firm. To do so, the paper uses two different identification strategies, one based on foreign demand and transportation costs, and the other using the Muslim boycott of Danish exports after the Cartoon crisis. Both of these identification strategies result in robust effects of trade shocks on within-firm inequality through changes in the number of management layers. The evidence from the paper is consistent with models of knowledge-based hierarchies. He finds that adding a hierarchy layer significantly increases inequality within firms, ranging from $2 \%$ for the 50-10 wage gap to $4.7 \%$ for the 90-50 wage gap. These results reinforce our finding that reorganization can be an important channel by which trade affects wage inequality.

In this paper our focus has been mostly in the reorganization associated with entry/exit behavior in foreign markets and the effects on layer-level changes in wages, span of control, and knowledge composition. We have not explored the reverse channel by which organization affects trade, which is of course present in the general equilibrium theory of CRH. Spanos (2016c) complements our findings for France by looking at the effect of organization on export performance. He uses a similar dataset as our study and shows evidence that firms with more layers sell a larger number of products, and to more destinations, compared to the ones with fewer layers. He identifies these export margins as the ones more correlated to productivity and number of layers. In fact, these results complement nicely with the study on Portugal by Mion, Opromolla, and Sforza (2016), who find that export experience acquired by managers in past organizations can result in more exports in their current firm. Put together, these results underscore that the channel from organization to export performance is also important and active in the data on top of the effect of exporting on organization that we have documented.

\subsection{Other Outcomes}

The studies above look at the two-way link between organization and some firm level outcomes, including their participation in export markets. We have argued that this is important because the way firms organize determines their productivity and costs. Several papers have studied the link between organizational change and productivity. For example, Caliendo, Mion, Opromolla and Rossi-Hansberg (2015) show that the reorganization of firms is an important source of the aggregate productivity gains in the Portuguese economy. They first document that the empirical patterns in the Portuguese economy match the theoretical predictions of CRH. They then study empirically the prediction of the $\mathrm{CRH}$ model, that reorganization reduces the marginal cost of the firm, and therefore prices, while increasing the physical productivity of the firm by reducing 
average variable cost. As a result, revenue based productivity should fall, while quantity based productivity should increase, as firms add layers. The results are stark. The study does not find any case in which the evidence can falsify this prediction on how a reorganization affects both types of firm productivity. Moreover, the paper presents some evidence of a causal effect of changes in layers on productivity, using firm specific exchange rates based on a firm's import and export patterns. In sum, changes in organization affect significantly the physical productivity of the firm. For France, Spanos (2016a) finds that firms in larger markets have more layers and are more productive. Furthermore, Spanos (2016a) finds that between $8 \%$ and $40 \%$ of the productivity differences across locations within France can be explained by firms having a greater number of layers and more complex organizations. This provides a relevant rationale for why we care about the results on export opportunities and organization that we have documented in this paper.

Finally, more recent research has also shown that using organizations can help to shed light on business creation. In particular, using a sample of 16 million observations of Swedish workers and occupational categories, Tåg, Åstebro, and Thompson (2016) provide evidence that the hierarchical structure of a firm matters for the likelihood of business creation among its former employees. The results are striking; employees at the highest layers, namely CEOs, directors, and senior staff, are three to four times more likely than production workers to found a limited liability company. Unfortunately, given data limitations, the results cannot be interpreted as casual.

\section{Conclusion}

A firm's sales in foreign markets are correlated with a variety of firm level outcomes. Some of them are well known. For example, we know that trade makes firms more productive and larger in terms of total sales and employment. In this paper we show that exporting is also associated with firm reorganizations. Firms that start to trade are more likely to add management layers. In fact, among all the firms that start to trade, the ones that grow significantly are the ones that reorganize. These firms also exhibit particular patterns for wages and employment in preexisting layers. In particular, the firms that reorganize when they start exporting pay workers in preexisting

layers less, and workers in the top new layer much more. So, wage inequality within those firms increases. In contrast, firms that start to export but do not reorganize increase wages modestly at all layers.

Our first set of results only describes an equilibrium relationship between exporting and organization, not a causal effect. As such, these results are helpful to discriminate between theories, but not to understand the impact of, say, a trade liberalization on organization. So, we attempt to go further and estimate causal effects using a Bartik-style shock. The results are encouraging in that the causal effects are in general, significant and large. Still, more work needs to be done in identifying instruments that produce a more systematic first stage. Other studies have tried a variety of other instruments in other countries and yield results that are surprisingly consistent with ours. 
All together, the evidence that we have presented, as well as the one in the existing literature, is starting to paint a consistent picture in which part of the effect of access to foreign markets is realized through the reorganization of production. Furthermore, as we argued in the last section, a variety of studies have linked these reorganizations to changes in productivity.

Firms are complex organizations that react to changes in their environment. Only if we understand how globalization affects the internal structure of firms are we ever going to understand its full and true impact. We hope this research is starting to illuminate some of the contents of one of the more resilient black boxes in economics. 


\section{References}

[1] Bernini, M., Guillou, S., and T. Treibich, (2016), "Firm Export Diversification and Labor Organization," Working Paper

[2] Bernard, A. B. and J. B. Jensen, (1995), "Exporters, Jobs, and Wages in U.S. Manufacturing: 1976-1987," Brookings Papers in Economic Activity. Microeconomics, 67-112.

[3] Bernard, A. B. and J. B. Jensen, (1997), "Exporters, Skill Upgrading and the Wage Gap," Journal of International Economics, 42, 3-31.

[4] Bernard, A. B. and J. B. Jensen, (1999), "Exceptional Exporter Performance: Cause, Effect, or Both?," Journal of International Economics, 47:1, 1-25.

[5] Bernard, A. B, J. B. Jensen, S. Redding and P. Schott, (2007), "Firms in International Trade," Journal of Economic Perspectives, 21:3, 105-130.

[6] Bertrand, M., (2004), "From the invisible handshake to the invisible hand? How import competition changes the employment relationship," Journal of Labor Economics, 22:4, 723765 .

[7] Brambilla, I. D. Lederman, and G. Porto (2012), "Exports, Export Destinations and Skills," American Economic Review, Vol. 102, No. 7, 3406-3438.

[8] Caliendo, Lorenzo, Ferdinando, Monte, and Esteban Rossi-Hansberg, (2015), "The Anatomy of French Production Hierarchies," Journal of Political Economy, 123 (4): 809:852.

[9] Caliendo, L, G Mion, L. Opromolla, and E. Rossi-Hansberg, (2015), "Productivity and Organisation in Portuguese Firms," CEPR Discussion Papers 10993.

[10] Caliendo, L. and E. Rossi-Hansberg, (2012), "The Impact of Trade on Organization and Productivity," Quarterly Journal of Economics,127(3): 1393-1467.

[11] Cruz, M, M. Bussolo and L. Iacovone, (2016), "Organizing Knowledge to Compete: Impacts of capacity building programs on firm organization," Policy Research Working Paper Series 7640, The World Bank.

[12] Eaton, J., S. Kortum, F. Kramarz, and R. Sampognaro, (2011a), "Dissecting the French Export Wage Premium," Working Paper.

[13] Eaton, J., S. Kortum, and F. Kramarz (2011b), "An Anatomy of International Trade: Evidence from French Firms," Econometrica, 79:5, 1453-1498.

[14] Egger, H., and U. Kreickemeier, (2009), "Firm Heterogeneity and the Labor Market Effects of Trade Liberalisation," International Economic Review, 50: 187-216. 
[15] Felbermayr, G., J. Prat, and H. Schmerer, (2008), "Globalization and Labor Market Outcomes: Bargaining, Search Frictions, and Firm Heterogeneity," IZA discussion paper no. 3363.

[16] Friedrich, B.U., (2016), "Trade Shocks, Firm Hierarchies and Wage Inequality," Northwestern University, mimeo.

[17] Garicano, L., (2000), "Hierarchies and the Organization of Knowledge in Production," Journal of Political Economy, 108:5, 874-904.

[18] Helpman, E., O. Itskhoki, and S. Redding, (2010), "Inequality and Unemployment in a Global Economy," Econometrica, 78: 1239-1283.

[19] Melitz, M. J., (2003), "The Impact of Trade on Intra-Industry Reallocations and Aggregate Industry Productivity," Econometrica, 71:6, 1695-1725.

[20] Mion, G. and L.D. Opromolla, A. Sforza (2016), "The Diffusion of Knowledge via Managers' Mobility," CESifo WP 6256.

[21] Park, A., Yang, D., Shi, X. and Jiang, Y., (2010), "Exporting and firm performance: Chinese exporters and the Asian financial crisis," The Review of Economics and Statistics, 92:4, 822842.

[22] Revenga, A.L., (1992), "Exporting jobs?: The impact of import competition on employment and wages in US manufacturing," The Quarterly Journal of Economics, 107:1, 255-284.

[23] Roodman, D., (2011), "Estimating fully observed recursive mixed-process models with cmp," Stata Journal 11(2): 159-206.

[24] Rosen S., (1982), "Authority, control, and the distribution of earnings". Bell J. Econ. 13:311-23

[25] Spanos, Grigorios, (2016a), "The Impact of Market Size on Firm Organization and Productivity," Working Paper.

[26] Spanos, Grigorios, (2016b), "Sorting Within and Across French Production Hierarchies," Working Paper

[27] Spanos, Grigorios, (2016c), "Organization and Export Performance," Economic Letters 146:130-134.

[28] Tåg, J. 2013, "Production Hierarchies in Sweden," Economics Letters 121:2, 210-213.

[29] Tåg, J, T. Åstebro and P. Thompson 2016, "Hierarchies and Entrepreneurship," European Economic Review, 89, 129-147.

[30] Verhoogen, E. A., (2008), "Trade, Quality Upgrading, and Wage Inequality in the Mexican Manufacturing Sector," Quarterly Journal of Economics, 123:2, 489-530. 


\section{Appendix A - Supporting Tables}

Table A1-1 shows the relevant coefficients for equation (11.1) in model (11). Each row corresponds to a separate model estimate. $W_{L}^{(1)}$ and $W_{L}^{(2)}$ are measures of exogenous demand shocks as reported in the main text, and "p.v." are the associated p-values. Controls include year dummies and firm log value added at the beginning of the period. "model sig. p-value" reports the p-value for a test of the joint significance of model (11).

Table A1-1: Export Regression in Model 11

\begin{tabular}{cccccccc}
\hline \# of layers & $W_{L}^{(1)}$ & p.v. & $W_{L}^{(2)}$ & p.v. & controls & model sig. p-value & obs \\
\hline 0 & 0.006 & 0.65 & 0.113 & 0.61 & Yes & 0.00 & 1,557 \\
1 & -0.099 & 0.01 & -0.035 & 0.80 & Yes & 0.00 & 7,337 \\
2 & -0.033 & 0.20 & 0.021 & 0.68 & Yes & 0.00 & 29,965 \\
3 & -0.080 & 0.00 & 0.098 & 0.02 & Yes & 0.00 & 28,816 \\
\hline \hline
\end{tabular}

Table A1-2 shows the relevant coefficients for equations (12.1), marked "Dep. var.: $d \log X_{\text {Lit }}$ ",

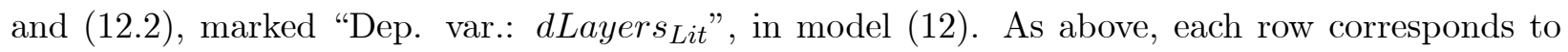
a separate model estimate. $W_{L}^{(1)}$ and $W_{L}^{(2)}$ are measures of exogenous demand shocks as reported in the main text, and "p.v." are the associated p-values, in equation (12.1). $\xi_{L}^{\ell}$ is the coefficient multiplying the log change in export, and "p.v" the associated p-value, in equation (12.2) Controls include year dummies and firm log value added at the beginning of the period. "model sig. p-value" reports the p-value for a test of the joint significance of model (12).

Table A1-2: Export regression and Ordered Probit for model 12

\begin{tabular}{cc|ccccc|ccc|cc}
\hline $\begin{array}{c}\text { \# of } \\
\text { layers }\end{array}$ & Layer & $W_{\text {Lit }}^{(1)}$ & p.v. & $W_{\text {Lit }}^{(2)}$ & p.v. & controls & $\xi_{L}^{\ell}$ & p.v. & controls & sig. p.v. & obs \\
\hline 0 & 0 & 0.007 & 0.71 & 0.104 & 0.74 & Yes & 1.138 & 0.00 & Yes & 0.00 & 1,557 \\
1 & 0 & -0.099 & 0.01 & -0.040 & 0.78 & Yes & 0.638 & 0.02 & Yes & 0.00 & 7,337 \\
1 & 1 & -0.100 & 0.01 & -0.034 & 0.85 & Yes & 0.477 & 0.28 & Yes & 0.00 & 6,854 \\
2 & 0 & -0.032 & 0.21 & -0.017 & 0.68 & Yes & 1.091 & 0.00 & Yes & 0.00 & 29,965 \\
2 & 1 & -0.033 & 0.21 & 0.014 & 0.73 & Yes & 1.082 & 0.00 & Yes & 0.00 & 29,965 \\
2 & 2 & -0.024 & 0.46 & -0.011 & 0.63 & Yes & 1.144 & 0.00 & Yes & 0.00 & 27,886 \\
3 & 0 & -0.081 & 0.00 & 0.098 & 0.02 & Yes & -0.058 & 0.87 & Yes & 0.00 & 28,816 \\
3 & 1 & -0.079 & 0.00 & 0.098 & 0.02 & Yes & -0.034 & 0.93 & Yes & 0.00 & 28,816 \\
3 & 2 & -0.078 & 0.02 & 0.096 & 0.02 & Yes & -0.084 & 0.83 & Yes & 0.00 & 28,816 \\
\hline \hline
\end{tabular}

